\title{
Problemas bioéticos na Estratégia Saúde da Família: reflexões necessárias
}

Selma Vaz Vidal ${ }^{1}$, Luís Cláudio de Souza Motta ${ }^{2}$, Andréia Patrícia Gomes ${ }^{3}$, Rodrigo Siqueira-Batista ${ }^{4}$

\section{Resumo}

Trata-se de revisão de literatura abordando os principais problemas éticos no âmbito da Estratégia Saúde da Família. Foram utilizados 15 artigos publicados no período de 1994 a 2012 e textos qualificados como complementares. Puderam ser destacadas, nos resultados, três grandes categorias de problemas bioéticos: 1) relações entre profissionais/trabalhadores e usuários do sistema de saúde; 2 ) relações entre profissionais/ trabalhadores no domínio da equipe; e 3) relações ético-políticas, afins à intersetorialidade, na esfera do Sistema de Saúde - e uma quarta categoria, ligada à esfera ambiental, que ainda necessita melhor delimitação empírica e conceitual. As considerações finais assinalam os principais complicadores para a adequada abordagem dos problemas bioéticos na Estratégia Saúde da Família e as possibilidades de seu equacionamento a partir do emprego de estratégias de educação permanente; e análise embasada nos referenciais teóricos da bioética da proteção e da bioética de intervenção.

Palavras-chave: Bioética. Estratégia Saúde da Família. Atenção primária à saúde.

\section{Resumen}

\section{Problemas bioéticos en la Estrategia Salud de la Familia: reflexiones necesarias}

Se trata de una revisión de la literatura abordando los problemas éticos clave dentro de la Estrategia Salud de la Familia. Se utilizaron 15 artículos publicados entre 1994 a 2012 y textos calificados como complementarios. Se han destacado en los resultados, tres grandes categorías de problemas bioéticos: 1 ) las relaciones entre profesionales/trabajadores y usuarios del sistema de salud; 2 ) las relaciones entre profesionales/ trabajadores en el ámbito del personal; y 3) las relaciones ético-políticas, en el ámbito del sistema de salud -y una cuarta categoría, vinculado a la esfera del medio ambiente, que todavía necesitan límites más empíricos y conceptuales. Las consideraciones finales indican la principal complicación el enfoque adecuado a los problemas bioéticos en Estrategia Salud de la Familia y las posibilidades de ecuación por medio del empleo de estrategias para la educación continua; y análisis empleando los principios teóricos de la bioética de protección y de la bioética de intervención.

Palabras-clave: Bioética. Programa de salud familiar. Atención primaria de la salud.

\section{Abstract}

\section{Bioethical Issues in the Family Health Strategy: relevant reflections}

This is a literature review aimed at key ethical problems within the Family Health Strategy. 15 articles published between 1994 and 2012 and texts considered complementary were used. It could be highlighted in the results, three major categories of bioethical issues: 1 ) those concerning relations between professionals/ workers and users of the health system; 2 ) those relating to relations between professionals/workers in the field of staff; and 3) those related to ethical-political relations, related to intersectionality, in the Health System sphere - and a fourth category, linked to the environmental sphere, which still needs better empirical and conceptual boundaries. The final considerations indicate the main complicating factors to a proper approach to the bioethical problems in Family Health Strategy and the possibilities of their addressing from the employment of strategies for continuing education and analysis based on the theoretical principles of bioethics protection and bioethics intervention.

Key words: Bioethics. Family health program. Primary health care.

1. Doutora vazvidal@yahoo.com.br - Prefeitura Municipal de Magé/RJ, Brasil e Programa de pós-graduação em Bioética, Ética Aplicada e Saúde Coletiva (PPGBIOS), Rio de Janeiro/RJ, Brasil 2. Doutorando Icsmotta@hotmail.com - Programa de pós-graduação em Bioética, Ética Aplicada e Saúde Coletiva (PPGBIOS), Universidade Federal do Rio de Janeiro (UFRJ) e Centro Universitário Serra dos Órgãos (Unifeso), Rio de Janeiro/RJ, Brasil 3. Doutora andreiapgomes@gmail.com - Universidade Federal de Viçosa, Viçosa/MG, Brasil 4. Doutor rsbatista@ufv.br - Programa de pós-graduação em Bioética, Ética Aplicada e Saúde Coletiva (PPGBIOS), Universidade Federal do Rio de Janeiro (UFRJ), Rio de Janeiro/RJ e Universidade Federal de Viçosa, Viçosa/MG, Brasil.

Correspondência

Selma Vaz Vidal - Rua Salma Repani, 31 CEP 29900-409. Magé/RJ, Brasil. 
A bioética e a Estratégia Saúde da Família (ESF) são domínios teórico-práticos capazes de unir a clínica e a saúde pública, sendo consideradas, por analogia, como genuínas pontes ${ }^{1}$. A bioética alude aos problemas morais que emergem da intervenção humana em diferentes campos, com destaque para aqueles inerentes às relações estabelecidas em todos os níveis da atenção à saúde. Enveredar-se nessa temática requer o auxílio de conceitos fundantes da ética, vez que os aspectos éticos da atenção à saúde nem sempre são visíveis aos gestores, usuários e trabalhadores da área da saúde e, ao final, interferem direta e indiretamente na consolidação do Sistema Único de Saúde (SUS).

O SUS é resultado de uma histórica luta pela democratização da saúde no Brasil, classicamente denominada Movimento da Reforma Sanitária, que teve seu apogeu na década de 80 , caracterizandose como importante mobilização nacional de reivindicações por mudanças, radicais, no ineficiente e insuficiente sistema sanitário vigente ${ }^{2}$. Destarte, buscava-se a ampliação da organização popular com a emergência de novos atores sociais, produzindo o incremento das demandas sociais sobre o Estado, em prol da universalização do acesso à saúde como direito fundamental para todos, domínios que serviram de subsídio para a elaboração do capítulo da saúde na Constituição da República Federativa do Brasil de $1988^{3}$.

Dessa forma, a criação do SUS abre perspectivas para apoiar ações no domínio social e na esfera pública, as quais possam garantir a participação popular na gestão. Ante essa realidade, a participação popular e o conhecimento da comunidade sobre o SUS se fazem de extrema importância, devido ao fato de que só é possível avançar na qualidade dos serviços e ações de saúde com a cooperação social efetiva, à medida que seus atores se tornem capazes de apontar os problemas e soluções relativas às díspares demandas ${ }^{4,5}$. Não obstante, para que isso aconteça é necessária a existência de espaços que possibilitem o empoderamento/a libertação dos cidadãos - no âmbito da reorganização do SUS -, no sentido de ampliar a inclusão social. Desde esta perspectiva, a Estratégia Saúde da Família (ESF) criada como Programa Saúde da Família (PSF) em 1994, pelo Ministério da Saúde - tem sido proposta como campo significativo para a transformação do modelo de atenção à saúde no país, provocando reflexões e mudanças nas instituições e na práxis dos cidadãos brasileiros ${ }^{6,7}$.

A ESF visa prestar atendimento de qualidade, integral e humanizado, em unidades municipais de atenção primária à saúde (APS), garantindo a reorganização da prática assistencial - em termos de ações de cuidado -, com foco na família. Ademais, reconhece a extrema relevância do ambiente físico e das relações sociais no processo saúde-doença, além de garantir a equidade no acesso à atenção em saúde ${ }^{6,8}$. Igualmente, possibilita o envolvimento com a comunidade, especialmente pela atuação dos agentes comunitários de saúde (ACS), e situa as equipes multiprofissionais mais próximas às pessoas em seus espaços de vida.

Dentre os princípios que norteiam a ESF, devem ser destacados: 1) processos de trabalho baseados nos conceitos de prevenção de agravos, promoção e vigilância da saúde; 2) a integralidade e a hierarquização vinculadas à rede de serviços, assegurando a referência e contrarreferência para os diversos níveis; e 3) a territorialização e a vinculação, provenientes do trabalho na microárea de abrangência, definida por meio do cadastramento e acompanhamento de determinado número de famílias por cada equipe ${ }^{8}$. Essa proposta objetiva substituir a forma de pensar e praticar saúde, transformando o tradicional modelo biomédico - prevalentemente curativo, que enfatiza o adoecimento individual e a assistência centrada nas especialidades desarticuladas - em uma clínica ampliada, multi e interprofissional, com foco na família e na comunidade ${ }^{3,9}$. Ademais, o desafio que se coloca é a transformação da assistência inscrita no procedimento para o cuidado à saúde centrado no usuário.

A transformação radical na lógica de operar no campo da saúde tem motivado questionamentos quanto ao papel da ESF na reformulação do SUS, uma vez que neste, não raras vezes, são mantidas estruturas atinentes ao tradicional modelo biomédico, o qual solapa o processo de trabalho no cotidiano do sistema de saúde ${ }^{10}$. Nesse sentido, o SUS vem seguindo um difícil processo de consolidação, principalmente no que tange à questão do financiamen- 
to, enfrentando um contexto que tornou premente a necessidade de se repensar sua organização na sustentabilidade do desenho atual. Tal contexto tem exposto diferentes níveis de problemas éticos - criando tensões que emanam da organização da rede de saúde, alcançando o âmago da equipe e o usuário -, os quais apresentam clara inter-relação com o domínio da bioética.

De fato, ao se considerar o conceito de bioética elaborado por Warren Thomas Reich na Enciclopédia norte-americana de bioética, edição revisada de 1995 - ou seja, um estudo sistemático das dimensões morais, incluindo visão moral, decisões, condutas e políticas, das ciências da vida e dos cuidados da saúde, empregando uma variedade de metodologias éticas em um ambiente interdisciplinar ${ }^{11}$-, percebe-se que se trata de um campo do conhecimento dirigido à abordagem das questões morais, procurando descrevê-las adequadamente para, ato contínuo, prescrever as melhores condutas, do ponto de vista do sujeito autônomo, racional e razoável, capaz de tomar decisões sobre o certo e o errado.

Tal proposição parte do pressuposto de que, em princípio, todo indivíduo racional é capaz de realizar julgamentos morais, capacidade que se desenvolverá mais ou menos, de acordo com as características e as oportunidades da interação dos sujeitos com o seu meio. De maneira geral, pode-se sintetizar essa evolução do desenvolvimento individual pelo deslocamento do julgamento alicerçado em razões heterônomas ao fundamentado em razões autônomas e prioridade dos interesses egoísticos para as análises baseadas em princípios éticos universais ${ }^{11}$. Neste movimento, as condições da interação dos indivíduos com seu meio social - e as oportunidades que esse meio social lhes oferece - tornam-se determinantes para a compreensão da sucessão de mudanças que ocorrem diuturnamente. Isto confere relevância aos processos de educação, tendo em vista o pressuposto de formação dos profissionais de saúde, não apenas nos aspectos técnicos, mas também éticos ${ }^{12}$.

Com essas preliminares considerações, tendo em vista as intersecções entre ESF e bioética e o reconhecimento de que, a priori, "toda ética é, antes, uma bioética" ${ }^{12}$, foi construída a pergunta norteadora para o desenvolvimento da investigação: "Quais problemas bioéticos são identificados no âmbito da
Estratégia Saúde da Família, em artigos indexados no período de 1994 a 2012?" Delineou-se o objetivo do ensaio, assim enunciado: descrever os principais problemas bioéticos presentes na APS/ESF, a partir de revisão de literatura.

\section{Método}

\section{Levantamento bibliográfico e seleção dos artigos}

O caminho percorrido na pesquisa diz respeito a uma revisão da literatura com estratégia de busca definida, utilizando a Biblioteca Virtual em Saúde (BVS). Os descritores empregados foram selecionados por meio de pesquisa aos 1) Descritores de Ciências da Saúde (DeCS) e 2) Medical Science Health (MeSH).

Os artigos que compuseram a amostra deste estudo contemplaram os seguintes critérios de inclusão: publicações no período de 1994 - ano de implantação do Programa Saúde da Família - a 2012; publicações em periódicos indexados; disponibilidade nas fontes de informação das bases de dados SciELO Brasil e Saúde Pública e Lilacs. Na base PubMed empreendeu-se a estratégia de busca com os seguintes unitermos: "Bioethics" e "Family Health Program" (Estratégia 1) e "Bioethics" e "Primary Health Care" (Estratégia 2). Os artigos foram filtrados com o operador padrão and, que inclui todas as palavras contidas nos descritores. Foram consideradas publicações em inglês, espanhol e português.

A seleção dos artigos para a composição da revisão baseou-se nos seguintes critérios: 1) abordagem de temática pertinente às questões bioéticas no âmbito da APS/ESF e 2) disponibilidade de acesso, via web ou Programa de Comutação Bibliográfica (Comut). Após a análise das citações obtidas, foram selecionados 15 artigos que compuseram o estudo.

\section{Análise dos artigos}

O material coletado passou por classificação de cunho analítico e gerou um quadro demonstrativo - com títulos dispostos em ordem crescente por ano de publicação -, no qual se buscou evidenciar o estado do conhecimento acerca das questões bioéticas atinentes ao espaço-tempo da APS/ESF. 
Quadro 1. Distribuição dos títulos, ano de publicação, métodos e problemas bioéticos identificados nos artigos sobre bioética e Estratégia Saúde da Família

\begin{tabular}{|c|c|c|}
\hline $\begin{array}{l}\text { Título (ano de } \\
\text { publicação) }\end{array}$ & Método & $\begin{array}{c}\text { Principais problemas bioéticos } \\
\text { identificados }\end{array}$ \\
\hline $\begin{array}{l}\text { Dilemas bioéticos } \\
\text { no cotidiano do } \\
\text { trabalho do agente } \\
\text { comunitário de } \\
\text { saúde (2004) }{ }^{13}\end{array}$ & $\begin{array}{l}\text { - Estudo qualitativo. Realização de grupo focal } \\
\text { com dinâmica de grupo } \\
\text { - Participantes do estudo: dois grupos de nove } \\
\text { agentes comunitários de saúde (ACS) } \\
\text { - Cenário: unidades da Secretaria Municipal de } \\
\text { Saúde de Recife }\end{array}$ & $\begin{array}{l}\text { - Formação técnica insuficiente dos } \\
\text { agentes comunitários de saúde } \\
\text { para atuação no SUS, nas situações } \\
\text { persistentes (violência, uso de drogas } \\
\text { ilícitas, gravidez precoce e aborto) }\end{array}$ \\
\hline $\begin{array}{l}\text { Bioética e atenção } \\
\text { básica: um perfil } \\
\text { dos problemas } \\
\text { éticos vividos } \\
\text { por enfermeiros } \\
\text { e médicos do } \\
\text { Programa Saúde da } \\
\text { Família, São Paulo, } \\
\text { Brasil (2004) }{ }^{14}\end{array}$ & $\begin{array}{l}\text { - Estudo empírico, qualitativo, de ética } \\
\text { descritiva, realizado a partir de entrevista } \\
\text { semiestruturada. Realizada análise categorial } \\
\text { temática, conforme proposto por Bardin } \\
\text { - Participantes do estudo: } 17 \text { enfermeiros e } 16 \\
\text { médicos } \\
\text { - Cenário: unidades básicas de saúde (PSF } \\
\text { implantado) do município de São Paulo }\end{array}$ & $\begin{array}{l}\text { - Problemas éticos nas relações com } \\
\text { usuários e família } \\
\text { - Problemas éticos nas relações da equipe } \\
\text { - Problemas éticos nas relações com a } \\
\text { organização e o sistema de saúde }\end{array}$ \\
\hline $\begin{array}{l}\text { Bioética e atenção } \\
\text { básica: um estudo } \\
\text { exploratório } \\
\text { dos problemas } \\
\text { éticos vividos por } \\
\text { enfermeiros e } \\
\text { médicos no PSF } \\
\text { (2006) }^{15}\end{array}$ & $\begin{array}{l}\text { - Estudo quantitativo, exploratório, de ética } \\
\text { descritiva. Coleta de dados com questionário } \\
\text { autoaplicado } \\
\text { - Participantes do estudo: } 24 \text { enfermeiros e } 22 \\
\text { médicos } \\
\text { - Cenário: unidades básicas de saúde (PSF } \\
\text { implantado) do município de São Paulo }\end{array}$ & $\begin{array}{l}\text { - Problemas éticos nas relações com } \\
\text { usuários e família } \\
\text { - Problemas éticos nas relações da equipe } \\
\text { - Problemas éticos nas relações com a } \\
\text { organização e o sistema de saúde }\end{array}$ \\
\hline $\begin{array}{l}\text { Enfermeiros } \\
\text { e usuários do } \\
\text { Programa Saúde } \\
\text { da Família: } \\
\text { contribuições } \\
\text { da bioética para } \\
\text { reorientar esta } \\
\text { relação profissional } \\
\text { (2007) }\end{array}$ & $\begin{array}{l}\text { - Estudo empírico, qualitativo, de ética } \\
\text { descritiva. Entrevista semiestruturada. } \\
\text { Realizada análise categorial temática, } \\
\text { conforme proposta por Bardin } \\
\text { - Participantes do estudo: } 17 \text { enfermeiros } \\
\text { - Cenário: unidades de Saúde da Família do } \\
\text { município de São Paulo }\end{array}$ & $\begin{array}{l}\text { - Problemas éticos nas relações com } \\
\text { usuários e família } \\
\text { - Problemas éticos nas relações da equipe } \\
\text { - Problemas éticos nas relações com a } \\
\text { organização e o sistema de saúde }\end{array}$ \\
\hline $\begin{array}{l}\text { Mulheres vivendo } \\
\text { com aids e os } \\
\text { profissionais do } \\
\text { Programa Saúde da } \\
\text { Família: revelando o } \\
\text { diagnóstico }(2008)^{17}\end{array}$ & $\begin{array}{l}\text { - Estudo descritivo qualitativo, com as } \\
\text { questões tratadas no campo da bioética. } \\
\text { Entrevistas com roteiro semiestruturado. } \\
\text { Realizada análise de conteúdo } \\
\text { - Participantes do estudo: seis mulheres } \\
\text { portadoras de HIV/aids } \\
\text { - Cenário: Secretaria Municipal de São Paulo, } \\
\text { Programa Saúde da Família e Serviço de } \\
\text { Atendimento Especializado }\end{array}$ & $\begin{array}{l}\text { - Questões relacionadas à privacidade e } \\
\text { à confidencialidade no relacionamento } \\
\text { entre o profissional e a paciente } \\
\text { - Problemas relacionados à autonomia do } \\
\text { usuário em decidir sobre a revelação de } \\
\text { informações à equipe do PSF } \\
\text { - Conflitos na manutenção do direito à } \\
\text { privacidade e no exercício do dever do } \\
\text { sigilo pelos profissionais da ESF }\end{array}$ \\
\hline $\begin{array}{l}\text { Problemas éticos na } \\
\text { atenção básica: a } \\
\text { visão de enfermeiros } \\
\text { e médicos (2009) }\end{array}$ & $\begin{array}{l}\text { - Investigação quanti-qualitativa, empírica, } \\
\text { de ética descritiva. Realizadas entrevistas } \\
\text { semiestruturadas (instrumento validado) e } \\
\text { análise de conteúdo } \\
\text { - Participantes do estudo: } 33 \text { médicos e } 30 \\
\text { enfermeiros } \\
\text { - Cenário: Centro de Saúde Escola, Estratégia } \\
\text { Saúde da Família e unidade básica de saúde }\end{array}$ & $\begin{array}{l}\text { - Problemas éticos nas relações com } \\
\text { usuários e família } \\
\text { - Problemas éticos nas relações da equipe } \\
\text { - Problemas éticos nas relações com a } \\
\text { organização e o sistema de saúde }\end{array}$ \\
\hline
\end{tabular}




\begin{tabular}{|c|c|c|}
\hline $\begin{array}{l}\text { Título (ano de } \\
\text { publicação) }\end{array}$ & Método & $\begin{array}{l}\text { Principais problemas bioéticos } \\
\text { identificados }\end{array}$ \\
\hline $\begin{array}{l}\text { Bioética e atenção } \\
\text { básica: para uma } \\
\text { clínica ampliada, } \\
\text { uma bioética clínica } \\
\text { amplificada (2009) }{ }^{19}\end{array}$ & $\begin{array}{l}\text { - Artigo de revisão } \\
\text { - Propõe que a clínica ampliada própria para a } \\
\text { atenção primária à saúde requer amplificação } \\
\text { da bioética clínica }\end{array}$ & $\begin{array}{l}\text { - Limites da relação profissional-usuário } \\
\text { - Desrespeito do profissional com o } \\
\text { usuário } \\
\text { - Desrespeito entre os profissionais de } \\
\text { saúde } \\
\text { - Necessidade da conjugação de direitos e } \\
\text { responsabilidades, por meio da ética do } \\
\text { cuidado }\end{array}$ \\
\hline $\begin{array}{l}\text { A percepção } \\
\text { do usuário do } \\
\text { Programa Saúde } \\
\text { da Família sobre } \\
\text { a privacidade e a } \\
\text { confidencialidade } \\
\text { das informações } \\
(2009)^{20}\end{array}$ & $\begin{array}{l}\text { - Estudo exploratório de corte qualitativo. } \\
\text { Entrevistas com roteiro semiestruturado. } \\
\text { Categorias de análise: direito; respeito; } \\
\text { diferencial de informações privativas } \\
\text { - Participantes do estudo: } 30 \text { usuários, maiores } \\
\text { de } 18 \text { anos } \\
\text { - Cenário: unidade básica de Saúde da Família } \\
\text { do município de São Paulo }\end{array}$ & $\begin{array}{l}\text { - A privacidade e a confidencialidade no } \\
\text { relacionamento entre o profissional e o } \\
\text { paciente }\end{array}$ \\
\hline $\begin{array}{l}\text { Processos de } \\
\text { trabalho no } \\
\text { Programa Saúde } \\
\text { da Família: } \\
\text { atravessamentos e } \\
\text { transversalidades } \\
(2009)^{21}\end{array}$ & $\begin{array}{l}\text { Pesquisa exploratória, com abordagem } \\
\text { qualitativa } \\
\text { - Participantes do estudo: três médicos, três } \\
\text { enfermeiras, dois técnicos de enfermagem e } \\
\text { quatro agentes comunitários de saúde } \\
\text { - Cenário: unidade de coleta de dados: técnica } \\
\text { de discussão focal e, posteriormente, análise } \\
\text { de conteúdo. ESF do município de Campo } \\
\text { Bom }\end{array}$ & $\begin{array}{l}\text { - Usuários: a demanda espontânea/ } \\
\text { independência em relação aos } \\
\text { integrantes da equipe de saúde } \\
\text { - Profissionais de saúde: } \\
\text { multidisciplinaridade, educação } \\
\text { continuada e permanente, estresse } \\
\text { do trabalho, intensa rotatividade dos } \\
\text { profissionais } \\
\text { - Gestores: modelo de gestão praticado } \\
\text { - Sistema de Saúde: questões atinentes } \\
\text { à referência e à contrarreferência, } \\
\text { predominância de modelo biomédico }\end{array}$ \\
\hline $\begin{array}{l}\text { O olhar da bioética } \\
\text { de intervenção } \\
\text { no trabalho do } \\
\text { cirurgião-dentista } \\
\text { do Programa Saúde } \\
\text { da Família (PSF) } \\
(2010)^{22}\end{array}$ & $\begin{array}{l}\text { - Estudo qualitativo. A coleta dos dados } \\
\text { ocorreu em duas etapas, envolvendo } \\
\text { questionários e entrevistas. Procedeu-se a } \\
\text { análise de conteúdo, conforme proposta por } \\
\text { Bardin } \\
\text { - Participantes do estudo: cirurgiões-dentistas } \\
\text { que compunham as equipes de ESF } \\
\text { - Cenário: unidades de Saúde da Família de } \\
\text { Florianópolis }\end{array}$ & $\begin{array}{l}\text { - Falhas no sistema referência/ } \\
\text { contrarreferência } \\
\text { - Questões atinentes à participação } \\
\text { popular e ao controle social na } \\
\text { manutenção do conselho de saúde } \\
\text { - Ineficiência das linhas de cuidados } \\
\text { quanto ao princípio da universalidade do } \\
\text { SUS }\end{array}$ \\
\hline $\begin{array}{l}\text { Acolhimento na } \\
\text { atenção básica: } \\
\text { reflexões éticas } \\
\text { sobre a atenção à } \\
\text { saúde dos usuários } \\
(2010)^{23}\end{array}$ & $\begin{array}{l}\text { Estudo com abordagem qualitativa e design } \\
\text { exploratório-descritivo. Realizada entrevista } \\
\text { semiestruturada e análise de conteúdo, } \\
\text { conforme proposta por Bardin } \\
\text { - Participantes do estudo: nove gestores, } 10 \\
\text { trabalhadores da saúde e sete usuários } \\
\text { - Cenário: rede básica de saúde de município } \\
\text { de grande porte no Estado de Santa Catarina }\end{array}$ & $\begin{array}{l}\text { - Limitação do acesso do usuário à saúde e } \\
\text { negação do direito } \\
\text { - Dificuldades no acolhimento e na } \\
\text { proteção dos usuários pelos membros } \\
\text { das unidades básicas de saúde } \\
\text { - Fragmentação dos serviços de saúde }\end{array}$ \\
\hline $\begin{array}{l}\text { Bioética da atenção } \\
\text { primária à saúde } \\
(2011)^{24}\end{array}$ & - Artigo de revisão & $\begin{array}{l}\text { - Problemas éticos relativos à demanda } \\
\text { - Questões éticas atinentes aos processos } \\
\text { de trabalho nos serviços de cuidados } \\
\text { primários }\end{array}$ \\
\hline
\end{tabular}




\begin{tabular}{|c|c|c|}
\hline $\begin{array}{l}\text { Título (ano de } \\
\text { publicação) }\end{array}$ & Método & $\begin{array}{c}\text { Principais problemas bioéticos } \\
\text { identificados }\end{array}$ \\
\hline $\begin{array}{l}\text { Capacitação em } \\
\text { bioética para } \\
\text { profissionais da } \\
\text { Saúde da Família do } \\
\text { município de Santo } \\
\text { André, SP (2012) }{ }^{25}\end{array}$ & $\begin{array}{l}\text { - Relato de experiência de capacitação de } 40 \\
\text { horas, com enfoque problematizador como } \\
\text { estratégia de ensino-aprendizagem, dirigido } \\
\text { à deliberação em bioética. Na análise, } \\
\text { estimou-se a mobilização na sensibilidade } \\
\text { para percepção de problemas éticos com a } \\
\text { aplicação de instrumentos antes e depois da } \\
\text { capacitação } \\
\text { - Participantes do estudo: seis médicos, seis } \\
\text { enfermeiros e um dentista } \\
\text { - Cenário: unidades da Estratégia Saúde da } \\
\text { Família, Santo André, SP }\end{array}$ & $\begin{array}{l}\text { - A formação de vínculos entre os } \\
\text { profissionais da ESF e os usuários } \\
\text { - Desenvolvimento de competência ética } \\
\text { dos profissionais da ESF } \\
\text { - Abordagem crítica da ética em saúde }\end{array}$ \\
\hline $\begin{array}{l}\text { Hermenêutica dos } \\
\text { problemas éticos } \\
\text { percebidos por } \\
\text { profissionais da } \\
\text { atenção primária } \\
(2012)^{26}\end{array}$ & $\begin{array}{l}\text { - Interpretação dos problemas éticos } \\
\text { evidenciados pela prática dos profissionais da } \\
\text { atenção primária oriundos de dois estudos: } \\
\text { 1) A percepção dos profissionais sobre os } \\
\text { aspectos éticos da Estratégia Saúde da Família } \\
\text { (ESF) no município de Campo Bom (RS) - } 2004 \\
\text { a 2006; e } \\
\text { 2) O discurso dos trabalhadores de uma } \\
\text { unidade básica de saúde (UBS) de São Leopoldo } \\
\text { (RS) sobre a humanização dos serviços - } 2007 \\
\text { a } 2009\end{array}$ & $\begin{array}{l}\text { - Problemas éticos nas relações com } \\
\text { usuários e família } \\
\text { - Problemas éticos nas relações da equipe } \\
\text { - Problemas éticos nas relações com a } \\
\text { organização e o sistema de saúde }\end{array}$ \\
\hline $\begin{array}{l}\text { O cuidado no } \\
\text { espaço-tempo } \\
\text { do Oikos: sobre } \\
\text { a bioética e a } \\
\text { Estratégia Saúde da } \\
\text { Família }(2012)^{27}\end{array}$ & $\begin{array}{l}\text { - Estudo com abordagem quanti-qualitativa. } \\
\text { Realizada aplicação de questionário e análise } \\
\text { de conteúdo, conforme proposta por Bardin } \\
\text { - Participantes do estudo: profissionais da } \\
\text { saúde que atuam na ESF } \\
\text { - Cenário: unidades da Estratégia Saúde da } \\
\text { Família, Teresópolis/RJ }\end{array}$ & $\begin{array}{l}\text { - Questões bioéticas relativas às tensões } \\
\text { entre equipe e usuários } \\
\text { - Questões bioéticas relativas às tensões } \\
\text { entre os próprios profissionais de saúde } \\
\text { - Importante dificuldade de reconheci- } \\
\text { mento, pelos profissionais, das questões } \\
\text { bioéticas atinentes ao processo de tra- } \\
\text { balho }\end{array}$ \\
\hline
\end{tabular}

Fonte: pesquisa bibliográfica realizada pelos autores.

Discutidas sob os referenciais teóricos pertinentes às linhas gerais de apreciação da questão norteadora que versa sobre a identificação dos problemas bioéticos, no período de 1994 a 2012, na ESF, são apresentadas a seguir.

\section{Resultados e discussão}

Dos artigos selecionados na amostra $(n=15)$ percebe-se que nove trabalharam com o método qualitativo, denotando certa predileção por essa estratégia de pesquisa por parte dos autores que elaboram os estudos bioéticos dirigidos à ESF/APS. Ademais, cabe destaque para a predileção pela investigação empírica, na medida em que a mesma, no entender de Zoboli, trata-se de um meio para conhecer, compreender e avaliar como os profissionais de saúde lidam com as questões da prática clínica, desvelando suas visões, atitudes e valores ${ }^{25}$.
Os resultados/considerações dos artigos do presente estudo demonstram que somente poucos autores referem e realizam a análise dos dados da pesquisa à luz das correntes da ética e das teorias da bioética. Nesse âmbito, duas correntes de pensamento bioético foram utilizadas prioritariamente - 0 principialismo e o utilitarismo -, a despeito da pouca elaboração argumentativa em torno dos problemas atinentes ao SUS. Igualmente foram constatadas poucas publicações sobre a temática bioética e APS/ ESF na forma de artigos no período de 1994 a 2012.

No exame dos elementos que compõem os artigos selecionados foi possível perceber a convergência para três principais ordens de problemas bioéticos: 1 ) as relações entre os profissionais/trabalhadores - vale a ressalva de que neste estudo considerou-se a distinção entre profissionais e trabalhadores de saúde, em concordância com a classificação do Código Brasileiro de Ocupações ${ }^{28}$ - e os usuários do sistema de saúde; 2) as relações entre os profissionais/trabalhadores no 
domínio da equipe e 3) as relações ético-políticas da intersetorialidade na esfera do SUS. Tal delimitação, pormenorizada em seguida, está intimamente articulada aos resultados da pesquisa realizada por Zoboli e Fortes ${ }^{14}$. Deve ser destacado que os artigos apontaram para a centralidade dos problemas éticos que interpenetram as relações conflituosas, os quais nem sempre são identificados pelos profissionais/trabalhadores da equipe de saúde como questões bioéticas.

Uma quarta ordem percebida pelos autores desse ensaio - mas não trabalhada nos artigos selecionados - diz respeito aos problemas bioéticos da saúde vinculados à esfera ambiental, os quais serão brevemente comentados.

Problemas bioéticos nas relações profissionais/trabalhadores e usuários do SUS na ESF

Foram identificadas dificuldades dos profissionais/trabalhadores na relação com o usuário/família, as quais dizem respeito ao estabelecimento de limites éticos e terapêuticos para atuação no estilo de vida das pessoas, tendo em vista os determinantes do processo saúde-doença. Pode-se agrupá-los em duas ordens de questões principais:

- A comunicação entre profissional/trabaIhador e usuário

A comunicação realizada por meio da relação dialógica, como parte do acolhimento, é o centro para a formação do vínculo da equipe de ESF com o usuário do sistema de saúde. Tal esfera abrange questões bioéticas - habitualmente relacionadas aos "ruídos de comunicação" -, dado que a 'tecnologia' das relações é uma das mais complexas, por incluir conhecimentos, habilidades e comportamentos e requerer atitudes de respeito entre pessoas. A comunicação configura ação intencionalmente dirigida e orientada, sendo "algo que se constrói" com base na escuta do outro - para compreender crenças, situação e possibilidades - com vistas à atuação conjunta no processo saúde-doença. Essa abordagem dialógica e emancipatória tem como pressuposto que todas as pessoas têm o direito a escoIher o caminho mais apropriado para promover, manter e recuperar sua saúde ${ }^{14,29,30}$.

- O exercício profissional do sigilo, da confidencialidade e da privacidade como direito do usuário

Reconhece-se que o sigilo, a privacidade e a confidencialidade são condições inerentes ao exercício profissional na área da saúde. A ESF tem conformação diferenciada, por nortear-se para o cuidado centrado no usuário e na família e agregar os ACS, moradores da comunidade, como parte da equipe de saúde. Quando o usuário fornece informações secretas sobre si mesmo - ou aspectos são identificados no exame clínico - para o profissional de saúde, o sigilo manifesta-se na perspectiva da confidencialidade, da discrição, da lealdade e da fidelidade, para além da abordagem deontológica ${ }^{24,26}$. Paul Ramsey argumenta que a questão ética fundamental na pesquisa e na assistência à saúde é a seguinte: Qual é o significado da lealdade de um ser humano para com outro? ${ }^{31}$ É possível reconhecer que a lealdade representa aspecto essencial para a conduta moral, ressaltando-se a obrigação da veracidade, da confiabilidade e da fidelidade, as quais devem estar imbricadas na relação profissional que se estabelece com o usuário ${ }^{30}$.

\section{Problemas bioéticos entre os profissionais/traba- Ihadores da ESF}

Os textos obtidos referem um conjunto de situações cotidianas no âmbito da ESF - atinentes à convivência entre os profissionais/trabalhadores -, as quais albergam problemas bioéticos, destacandose a falta de compromisso, de companheirismo e colaboração entre os membros da ESF, o desrespeito e o despreparo para o trabalho em equipe, as dificuldades na delimitação do campo de atuação das profissões, os questionamentos no desenvolvimento das atividades clínicas, as omissões relativas às ações de cuidado, a quebra do sigilo e a não solicitação de consentimento aos usuários do SUS, nos casos de publicação científica ${ }^{14,15,20,32}$.

Com base nessas conjecturas, as tensões nas relações estabelecidas entre os membros da equipe da ESF exprimem dúvidas acerca da autonomia e da responsabilidade dos profissionais/trabalhadores da equipe de saúde, as quais podem ser abordadas sob a perspectiva de distintas teorias éticas ${ }^{16,30}$, como as correntes consequencialistas e deontológicas. Ainda nesse âmbito, destaca-se que o trabalho em equipe abrange a necessidade de articulação intersetorial, no que tange aos problemas bioéticos das situações persistentes, tais como violência doméstica, uso de drogas, prostituição, gravidez precoce e aborto clandestino, dentre outras ${ }^{33}$

Os problemas bioéticos entre os profissionais/ trabalhadores podem ser transformados em desafios a ser vencidos coletivamente, com a continuidade do processo educacional formativo que contenha elementos promotores de condutas assertivas. 
Problemas bioético-políticos de intersetorialidade na esfera do sistema de saúde

Os aspectos agrupados nessa categoria são abrangentes e explicitam diferentes fragilidades no processo de consolidação do SUS. Foi possível destacar as seguintes questões: insalubridade associada à precária estrutura física das unidades básicas de Saúde da Família (UBSF); dificuldades para a realização da visita domiciliar (quantitativo insuficiente de ACS, pouca disposição da equipe técnica para as visitas, dentre outras); falta de apoio da gestão para discutir e resolver os conflitos éticos no ambiente de trabalho (por exemplo, o atravessamento de questões políticas eleitorais; a falta de promoção de capacitação e educação permanente); limitações da rede de saúde do município, incluindo número insuficiente de unidades da ESF, demanda clínica além da capacidade instalada, inoperância do sistema de referência/contrarreferência, dentre outras. Em síntese, tais questionamentos dizem respeito à gestão do cuidado em saúde e das pessoas. A constituição do SUS representou - para gestores, trabalhadores e usuários do sistema - nova forma de pensar, estruturar, desenvolver e produzir serviços e assistência em saúde, vez que os princípios da universalidade de acesso, integralidade da atenção à saúde, equidade, participação da comunidade, respeito à autonomia das pessoas e descentralização tornaram-se o norte para as práticas ${ }^{34}$.

Nesse contexto, existe uma situação crítica no que tange aos vínculos de trabalho no SUS - na área de competência municipal -, que é a precariedade do trabalho ${ }^{34}$, na medida em que se vive, hodiernamente, circunstâncias que envolvem diversos tipos de nomeações, as quais não garantem os direitos trabalhistas e previdenciários consagrados em lei, bem como a ausência de concurso público ou do processo de seleção pública para ocupação de cargos na ESF. Isso gera situações de rotatividade dos membros da equipe, baixos salários - com complementação por produtividade - e instabilidade, contexto que se torna ainda mais complexo diante do surgimento de outras modalidades de gestão da ESF, tais como a terceirização por fundações estatais e por organizações sociais (OS) ${ }^{35,36}$.

O conceito de gestão urge ser ampliado, de modo a abranger as funções administrativas e políticas para a efetivação dos planos de carreiras, cargos e salários (PCCS), na lógica da meritocracia e de novos arranjos para a democracia institucional. A gestão inclui ainda, em seu bojo, a função educativa, que tem como tônica a qualificação e a capacitação para o exercício do profissional/trabalhador, em caráter emancipatório com a implicação de seus atores ${ }^{37}$. Para o alcance de tal fim, a formação do profissional/trabalhador deve estar incluída nos diversos planos de trabalho anuais e ser aprovada e acompanhada pelos conselhos municipais de saúde.

Os problemas bioético-políticos expressam a complexidade existente nos segmentos da promoção social dentro do Estado brasileiro, como a garantia de serviços com qualidades, relativos à educação, à moradia, ao transporte, ao trabalho, à segurança pública, à seguridade social, ao esporte, ao lazer e à saúde. Por pertencerem a um contexto macropolítico, nem sempre os profissionais do SUS - mais especificamente da ESF - atentam para a possibilidade de compartilhamento dos problemas no campo da saúde com a intersetorialidade, no qual as necessidades não resolvidas vão se constituindo em situações bioéticas persistentes, as quais poderão ser adequadamente analisadas pelos referenciais da bioética da proteção ${ }^{38,39}$ e da intervenção ${ }^{40,41}$. Assim, poder-se-ia obter significativo ganho na interlocução com as secretarias de educação, de meio ambiente (essencial para a próxima ordem de problemas a ser abordada) e setores do Sistema Único de Assistência Social (Suas) - este último compõe uma rede protetiva ao cidadão, que identifica as demandas, vulnerabilidades e riscos, configurando-se em sistema público que organiza, de forma descentralizada, os serviços sócio-assistenciais no Brasil ${ }^{42}$.

Problemas bioéticos vinculados à esfera ambiental: uma quarta ordem de questões, aguardando investigação

Os componentes ambientais que determinam o adoecimento da população deveriam ocupar papel primordial nas ações de cuidado, desenvolvidas pela equipe multiprofissional da ESF e dirigidas ao usuário do SUS. Ainda que esses aspectos não tenham sido delimitados, claramente, como categorias identificadas pelos autores dos artigos selecionados na presente investigação, alguns aspectos relacionados às interseções saúde/ambiente puderam ser identificados nos textos escolhidos e em outras fontes bibliográficas consultadas ${ }^{43,44}$. Há diferente vulnerabilidade para a aquisição de doenças relacionadas ao ambiente nas regiões brasileiras, as quais são pouco abordadas do ponto de vista da ESF ${ }^{43}$, destacando-se como entidades mórbidas significativas: asma; pneumoconiose; câncer de pulmão; doenças infecciosas - tanto emergentes quanto reemergentes, com destaque para as zoonoses em centros urbanos -; intoxicações exógenas, sobretudo por pesticidas, dentre outras ${ }^{42,44}$. 
A interdependência entre saúde e determinantes ambientais tem interface com a bioética contemporânea, a qual precisa ser mais bem explorada, de modo a auxiliar a tomada de decisão em respeito às ações efetivas de promoção e proteção à saúde. Tal proposição torna-se mais clara ao se reconhecer que a bioética, em suas origens, traz um discurso com marcante preocupação ecológica, o que aponta para a intrínseca interseção entre as duas disciplinas. De fato, ao ser proposta pelo oncologista Van Rensselaer Potter, em 1970, a bioética foi caracterizada como nova ética científica capaz de dar respostas aos problemas advindos das relações homem/natureza - entendendo-se que o primeiro comportava-se como verdadeiro câncer para o planeta Terra - , cujos objetivos principais seriam garantir a perpetuação da espécie humana e de sua qualidade de vida ${ }^{45}$.

\section{Considerações finais}

A revisão da literatura realizada no presente artigo permitiu a identificação de relevantes problemas bioéticos no espaço-tempo da APS/ESF, com ênfase especial para três ordens de questões, concordes à originária descrição de Zoboli e Fortes ${ }^{14}:$ 1) problemas éticos nas relações com usuários e família; 2) problemas éticos nas relações da equipe; 3) problemas éticos nas relações com a organização e o sistema de saúde. Tais situações emergem, em grande medida, dos contatos contínuos entre os profissionais e os usuários do SUS, habitualmente em situações de menor urgência - peculiaridade da APS -, o que pode tornar os problemas com aparência menos dramática, ainda que sua complexidade não seja menor, em relação às questões vividas nos grandes complexos hospitalares ${ }^{46-48}$.

Dentre os complicadores identificados para a adequada abordagem dos problemas bioéticos na APS/ESF merecem destaque a invisibilidade dos mesmos para os profissionais de saúde que atuam nesse nível de atenção e as dificuldades teóricas para a proposição de soluções para as questões observadas. Em relação ao primeiro ponto, é possível formular a hipótese, sob o prisma educativo, de que tais problemas bioéticos poderiam ser adequadamente encaminhados com a implementação de espaços de educação permanente na equipe da $E S F$, os quais poderiam ser extremamente fecundos para o estabelecimento do diálogo - as boas conversações -, concorrendo, assim, para a construção de relações mais fraternas entre os membros da equipe. Em relação ao segundo, o emprego de correntes bioéticas originalmente propostas para a interseção clínica/saúde pública - como a bioética da proteção e a bioética de intervenção - poderá auxiliar substantivamente o equacionamento das situações.

É possível conjecturar que a reflexão bioética poderá direcionar a delimitação dos problemas e a proposição das melhores condutas para os mesmos, à medida que os profissionais/trabalhadores se ouçam, no domínio pertinente às suas atribuições e à participação nas tomadas de decisões no âmbito da equipe. Trata-se de uma aposta na indissociabilidade entre trabalho/formação - quiçá consubstanciada na criação de espaços de educação permanente -, considerando-se o desenvolvimento dos trabalhadores da ESF, a pluralidade das pessoas e as circunstâncias que se modificam sob a influência de diversos fatores, que têm na bioética a ponte que une o biológico às humanidades.

Este artigo é parte da tese de S. V. Vidal, intitulada Bioética, educação e Estratégia Saúde da Família: entre práxis e paidéia, que se articula ao projeto Bioética na formação do profissional de saúde: construindo discursos e práxis no espaço-tempo da Estratégia Saúde da Família, realizado com apoio do CNPq na pós-graduação em Bioética, Ética Aplicada e Saúde Coletiva (PPGBIOS).

\section{Referências}

1. Rego S, Palácios M, Siqueira-Batista R. Bioética para profissionais de saúde. Rio de Janeiro: Editora Fiocruz; 2009.

2. Labra ME, Figueiredo JSA. Associativismo, participação e cultura cívica: o potencial dos conselhos de saúde. Ciênc Saúde Coletiva. 2002;7(3):537-47.

3. Cotta RMM, Mendes FF, Muniz JN. Descentralização das políticas púiblicas de saúde: do imaginário ao real. Viçosa: Ed. UFV/Cebes; 1998.

4. Andrade GRB, Vaitsman J. Apoio social e redes: conectando solidariedade e saúde. Ciênc Saúde Coletiva. 2002;7(4):925-34.

5. Guizardi FL, Pinheiro R. Dilemas culturais, sociais e políticos da participação dos movimentos sociais nos conselhos de saúde. Ciênc Saúde Coletiva. 2006;11(3):797-805. 
6. Fernandes AS, Seclen-Palacin J, organizadores. Experiências e desafios da atenção básica e saúde da família: caso Brasil. Brasília: Opas; 2004.

7. Martins PC, Cotta RMM, Mendes FF, Franceschinni SCC, Priore SE, Dias G et al. Conselhos de saúde e a participação social no Brasil: matizes da utopia. Physis. 2008;18(1):105-21.

8. Brasil. Ministério da Saúde. Secretaria de Atenção à Saúde. Departamento de Atenção Básica. Avaliação normativa do Programa Saúde da Família no Brasil: monitoramento da implantação e funcionamento das equipes de saúde da família - 2001/2002. Brasília: MS/Secretaria de Atenção à Saúde/Departamento de Atenção Básica; 2004.

9. Cotta RMM, Morales MSV, Cotta Filho JS, Gonzáles AL, Ricós JAD, Real ER et al. Obstáculos e desafios da saúde pública no Brasil. Revista do Hospital das Clínicas de Porto Alegre. 2002;22(1):2532.

10. Matumoto S, Fortuna C, Mishima S, Pereira MJB, Domingos NAM. Supervisão de equipes no Programa de Saúde da Família: reflexões acerca do desafio da produção de cuidados. Interface Comun Saúde Educ. 2005;9(6):9-24.

11. Reich WT, editor. Encyclopedia of bioethics. Rev ed. New York: Macmillan; 1995. p. 1.639-44.

12. Schramm FR. Toda ética é, antes, uma bioética. Humanidades. 1994;9(4):324-31.

13. Fontoura MD, Almeida AP, Marques CMS, Prado MM, Portillo JAC. Dilemas bioéticos no cotidiano do trabalho do agente comunitário de saúde. Rev Saúde Dist Fed. 2004;15:67-77.

14. Zoboli ELCP, Fortes PAC. Bioética e atenção básica: um perfil dos problemas éticos vividos por enfermeiros e médicos do programa saúde da família, São Paulo, Brasil. Cad Saúde Pública. 2004;20(6):1.690-9.

15. Silva LT, Zoboli ELCP, Borges ALV. Bioética e atenção básica: um estudo exploratório dos problemas éticos vividos por enfermeiros e médicos no PSF. Cogitare Enferm. 2006;11(2):133-42.

16. Zoboli ELCP. Enfermeiros e usuários do programa saúde da família: contribuições da bioética para reorientar esta relação profissional. Acta Paul Enferm. 2007;20(3):316-20.

17. Ferreira FC, Nichiata LYI. Mulheres vivendo com aids e os profissionais do Programa Saúde da Família: revelando o diagnóstico. Rev Esc Enferm USP. 2008;42:483-9.

18. Lima AC, Morales DA, Zoboli ELCP, Sartório NA. Problemas éticos na atenção básica: a visão de enfermeiros e médicos. Cogitare Enferm. 2009;14(2):294-303.

19. Zoboli ELCP. Bioética e atenção básica: para uma clínica ampliada, uma bioética clínica ampliada. O Mundo Saúde. 2009;33:195-204.

20. Seoane AF, Fortes PAC. A percepção do usuário do programa saúde da família sobre a privacidade e a confidencialidade de suas informações. Saúde Soc. 2009;18(1):42-9.

21. Junges JR, Selli L, Soares NA, Fernandes RBP, Schreck M. Processos de trabalho no Programa Saúde da Família: atravessamentos e transversalidades. Rev Esc Enferm USP. 2009;43(4):937-44.

22. Gonçalves ER, Ramos FRS, Garrafa V. O olhar da bioética de intervenção no trabalho do cirurgiãodentista do programa saúde da família (PSF). Rev. bioét. (Impr.). 2010;18(1):225-39.

23. Brehmer LCF, Verdi M. Acolhimento na atenção básica: reflexões éticas sobre a atenção à saúde dos usuários. Ciênc Saúde Coletiva. 2010;15(Supl.3):3.569-78.

24. Junges JR. Bioética da atenção primária à saúde. Revista AMRIGS. 2011;55(1):88-90.

25. Zoboli ELCP, Soares FAC. Capacitação em bioética para profissionais da saúde da família do município de Santo André, SP. Rev Esc Enferm USP. 2012;46(5):1.248-53.

26. Junges JR, Schaefer R, Nora CRD, Basso M, Silocchi C, Souza M et al. Uma hermenêutica de problemas éticos percebidos por profissionais da atenção primária. Rev. bioét. (Impr.). 2012;20:97-105.

27. Motta LCS. O cuidado no espaço-tempo do Oikos: sobre a bioética e a estratégia de saúde da família [resumo]. Rev Bras Educ Méd. 2012;36(4):581.

28. Brasil. Ministério do Trabalho e Emprego. Secretaria de Políticas de Emprego e Salários. Classificação Brasileira de Ocupações (СBO). [Internet]. 2002 (acesso 15 jan. 2011). Disponível: http://www.mtecbo.gov.br/cbosite/pages/informacoesGerais.jsf;jsessionid=25210410A30B356 C1FFDEECE1C521FFA

29. Chiesa AM, Veríssimo MLOR. A educação em saúde na prática do PSF. In: Instituto para o Desenvolvimento da Saúde. Universidade de São Paulo. Ministério da Saúde. Manual de Enfermagem. Brasília: Ministério da Saúde; 2001. p 34-42.

30. Beauchamp TL, Childress JF. Princípios de ética biomédica. São Paulo: Loyola; 2002.

31. Ramsey P. The patient as person. New Haven: Yale University Press; 1970. p. xii.

32. Zoboli ELCP. Deliberação: leque de possibilidades para compreender os conflitos de valores na prática clínica da atenção básica. [livre-docência]. São Paulo: Escola de Enfermagem da Universidade de São Paulo; 2010. p. 35.

33. Costa EMA. Saúde da família: uma abordagem multidisciplinar. $2^{a}$ ed. Rio de Janeiro: Editora Rubio; 2009.

34. Siqueira-Batista R, Gomes AP, Albuquerque VS, Cavalcanti FOL, Cotta RMM. Educação e competências para o SUS: é possível pensar alternativas à(s) lógica(s) do capitalismo tardio? Ciênc Saúde Coletiva. 2013;18(1):159-70.

35. Pires DE. Precarização do trabalho em saúde. In: Dicionário da educação profissional em saúde. [Internet]. Rio de Janeiro: Fundação Oswaldo Cruz; 2009 (acesso 10 jan. 2011). Disponível: http:// www.epsjv.fiocruz.br/dicionario/verbetes/pretrasau.html 
36. Cotta RMM, Schott M, Azeredo CM, Franceschini SCC, Priore SE, Dias G. Organização do trabalho e perfil dos profissionais do Programa Saúde da Família: um desafio na reestruturação da atenção básica em saúde. Epidemiol Serv Saúde. 2006;15(3 Suppl):7-18.

37. Mitre SM, Siqueira-Batista R, Girardi-de-Mendonça JM, Morais-Pinto NM, Meirelles CAB, PintoPorto $\mathrm{C}$ et al. Metodologias ativas de ensino-aprendizagem na formação profissional em saúde: debates atuais. Ciênc Saúde Coletiva. 2008;13(Suppl 2):2.133-44.

38. Schramm FR, Kottow M. Principios bioéticos en salud pública: limitaciones y propuestas. Cad Saúde Pública. 2001;17(6):949-56.

39. Schramm FR. A bioética de proteção é pertinente e legítima? Rev bioét (Impr). 2011;19:713-24.

40. Nascimento WF, Garrafa V. Por uma vida não colonizada: diálogo entre bioética de intervenção e colonialidade. Saúde Soc. 2011;20:287-99.

41. Silva LE, Drummond A, Garrafa V. Bioética de intervenção: uma prática politizada na responsabilidade social. Universitas: ciências da saúde. 2011;9:111-9.

42. Brasil. Ministério do Desenvolvimento Social e Combate à Fome. Sistema Único de Assistência Social (Suas). [Internet]. Brasília: MDS; 2010 (acesso 10 out. 2011). Disponível: http://www.mds. gov.br/assistenciasocial/suas

43. Guimarães FT, Vitorino RR, Netto Cézar PH, Castro JF, Cotta RMM, Bittencourt-Costa JR et al. Educação, saúde e ambiente: as concepções dos agentes comunitários de saúde. Ensino, Saúde e Ambiente. 2013;6(1):77-88.

44. Siqueira-Batista R, Rôças G, Gomes AP, Albuquerque VS, Araujo MBF, Messeder J. Ecologia na formação do profissional de saúde: promoção do exercício da cidadania e reflexão crítica comprometida com a existência. Rev Bras Educ Méd. 2009;33:271-5.

45. Motta LCS, Siqueira-Batista R, Vidal SV. Bioética: afinal o que é isto? Rev Bras Clín Méd. 2012;10:431-9.

46. Sugarman J, editor. Ethics in primary care. New York: McGraaw-Hill; 2000. p. xiii-xvi.

47. White BC, Zimbelman JA. Moral dilemmas in community health care: cases and commentaries. nd: Pearson; 2005.

48. Rego S. A formação ética do médico: saindo da adolescência com a vida (dos outros) nas mãos. Rio de Janeiro: Editora Fiocruz; 2003.

\section{Participação dos autores}

Selma Vaz Vidal, Andréia P. Gomes e Rodrigo Siqueira Batista desenharam o artigo. Selma Vaz Vidal participou, com Luiz Cláudio S. Motta, da elaboração, montagem da revisão e redação do texto. Rodrigo Siqueira-Batista orientou o trabalho de pesquisa, revisando com Andreia P. Gomes a versão final do manuscrito.

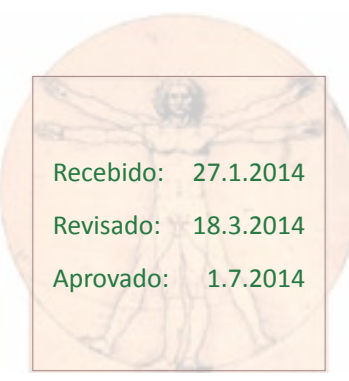

